City University of New York (CUNY)

CUNY Academic Works

\title{
Using Microwave Brightness Temperature Diurnal Cycle to Improve Emissivity Retrievals Over Land
}

\author{
Hamidreza Norouzi \\ CUNY New York City College of Technology \\ William Rossow \\ CUNY City College \\ Marouane Temimi \\ CUNY City College \\ Catherine Prigent \\ Observatoire de Paris \\ Marzieh Azarderakhsh \\ CUNY City College
}

See next page for additional authors

\section{How does access to this work benefit you? Let us know!}

More information about this work at: https://academicworks.cuny.edu/cc_pubs/219

Discover additional works at: https://academicworks.cuny.edu

This work is made publicly available by the City University of New York (CUNY).

Contact: AcademicWorks@cuny.edu 


\section{Authors}

Hamidreza Norouzi, William Rossow, Marouane Temimi, Catherine Prigent, Marzieh Azarderakhsh, Sid Boukabara, and Reza Khanbilvardi 


\title{
Using microwave brightness temperature diurnal cycle to improve emissivity retrievals over land
}

\author{
Hamidreza Norouzi ${ }^{\text {a,b,* }}$, William Rossow ${ }^{\text {b }}$, Marouane Temimi ${ }^{\mathrm{b}}$, Catherine Prigent ${ }^{\mathrm{c}}$,

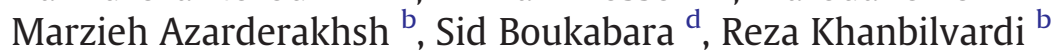 \\ a New York City College of Technology/CUNY, 300 Jay St., Brooklyn, NY 11201, USA \\ ${ }^{b}$ NOAA-Cooperative Remote Sensing Science and Technology Center (CREST), The City College of New York, 160 Convent Ave, New York, NY 10031, USA \\ ' Centre National de la Recherche Scientifique, Laboratoire d'Etudes du Rayonnement et de la Matière en Astrophysique, Observatoire de Paris, 61 avenue de l'Observatoire, \\ 75014 Paris, France \\ d National Oceanic and Atmospheric Administration (NOAA)/National Environmental Satellite, Data, and Information Service (NESDIS)/The Center for Satellite Applications and \\ Research (STAR), 5200 Auth Road, Camp Springs, MD 20746, USA
}

\section{A R T I C L E I N F O}

Article history:

Received 4 January 2012

Received in revised form 3 April 2012

Accepted 14 April 2012

Available online $\mathrm{xxxx}$

\section{Keywords:}

Emissivity

Brightness temperature

Diurnal cycle

Land

Passive microwave

Effective temperature

Vegetation

Soil moisture

\begin{abstract}
A B S T R A C T
To retrieve microwave land emissivity, infrared surface skin temperatures have been used as surface physical temperature since there is no global information on physical vegetation/soil temperature profiles. However, passive microwave emissions originate from deeper layers with respect to the skin temperature. So, this inconsistency in sensitivity depths between skin temperatures and microwave temperatures may introduce a discrepancy in the determined emissivity. Previous studies showed that this inconsistency can lead to significant differences between day and night retrievals of land emissivity which can exceed $10 \%$. This study proposes an approach to address this inconsistency and improve the retrieval of land emissivity using microwave observations from Advanced Microwave Scanning Radiometer-Earth Observing System (AMSR-E). The diurnal cycle of the microwave brightness temperature $(\mathrm{Tb})$ was constructed over the globe for different frequencies/polarizations using a constellation of satellites. Principal component analysis (PCA) was conducted to evaluate the spatial variation of the $\mathrm{Tb}$ diurnal cycle. The diurnal amplitudes of microwave temperatures observed in desert areas were not consistent with the larger amplitudes of the diurnal cycle of skin temperature. Densely vegetated areas with more moisture have shown smaller amplitudes. A lookup table of effective temperature $\left(T_{e f f}\right)$ anomalies is constructed based on the $\mathrm{Tb}$ diurnal cycle to resolve the inconsistencies between infrared and $\mathrm{Tb}$ diurnal variation. This lookup table of $T_{\text {eff }}$ anomalies is a weighted average over the layers contributing to the microwave signal, for each channel and month. The integration of this $T_{\text {eff }}$ in the retrieval of land emissivity reduced the differences between day and night retrieved emissivities to less than 0.01 for AMSR-E observations.
\end{abstract}

(c) 2012 Elsevier Inc. All rights reserved.

\section{Introduction}

Instantaneous measures of microwave brightness temperature, $T b$, have been used in a variety of applications to estimate column water vapor abundance, rainfall rate, surface ocean wind speed, ocean salinity, soil moisture, freeze/thaw state, land surface temperature, inundation fraction, and vegetation structure (Boukabara et al., 2007; Entekhabi et al., 2010; Fily et al., 2003; Karbou et al., 2006; McCollum and Ferraro, 2005; Min et al., 2010; Njoku et al., 2003; Papa et al., 2006; Tedesco and Kim, 2006; Wilheit et al., 2003; Zhang et al., 2010). Land surface properties can be inferred accurately if physical temperature and emissivity variations can be separated (Prigent et al., 1997). Diurnal synoptic and variations of land surface temperature, as well as the atmospheric temperature and water vapor profiles, affect the observed

\footnotetext{
* Corresponding author. Tel.: +1 718260 5410; fax: +1 7182605677. E-mail address: hnorouzi@citytech.cuny.edu (H. Norouzi).
}

$T b$. The more frequent the observation of $T b$ throughout the day, the better understanding of the variability of retrieved parameters.

Microwave emissions can come from layers deeper than the surface skin depending on the frequency and the media, in particular its moisture. For instance, in vegetated areas, the $6.9 \mathrm{GHz}$ ( $\mathrm{C}$ band) passive microwave can provide some soil moisture information as it is less affected by vegetation (Njoku et al., 2003). The diurnal variation of the passive microwave $T b$ mainly depends on physical temperature variation at the depth of origination. For some dry and porous surfaces, such as sand dunes in deserts, microwave temperature exhibits much smaller diurnal amplitude than surface temperature variation (Prigent et al., 1999). In some desert regions at higher frequencies, where the penetration depth is smaller, the radiometric measurements display diurnal variations similar to those of the surface temperature, but conversely, at lower frequencies, where the penetration depth is larger, the radiation displays smaller diurnal variations than the surface temperature (Grody and Weng, 2008). Therefore, to retrieve microwave emissivities, estimates of the variation of physical temperatures with depth are 
necessary. A physical model has been used to simulate the physical temperature variation at different depths based on a semi-infinite heat transfer equation (Grody and Weng, 2008; Prigent et al., 1999). This type of model shows decreasing diurnal amplitude and increasing phase lag with respect to the skin temperature with depth.

We found significant differences between land emissivities determined from AMSR-E daytime and nighttime overpasses (Norouzi et al., 2011), retrieved using the infrared thermal temperature as the physical temperature. The discrepancies between day and night emissivities have also been noticed in other studies (Moncet et al., 2011). Such large differences with a consistent feature (day to day) within one day, up to 0.1 , seem unlikely for stable surface conditions. The proposed explanation is that the skin temperature, $T s$, and $T b$, do not originate from the same depth, so that their diurnal cycles are not the same. This assumption is supported by the variation of the discrepancy magnitude with surface type-more densely vegetated locations that are also moister showed much smaller discrepancies than arid regions. Moncet et al (2011) used the physical model proposed by Prigent et al (1999) to produce a monthly mean emissivity with consideration of microwave penetration depth effect. However, there is no available instantaneous emissivity product yet that has considered the effect of penetration depth in the retrieval.

Polar orbiting satellites provide observations at most locations on the globe twice a day (except for Polar Regions which are observed more often). Since none of the available geostationary satellites is equipped with a passive microwave sensor, resolution of diurnal variations is not achievable for conical scanning sensors except by aggregating observations from multiple satellites. Several sensors, such as the Scanning Multi-channel Microwave Radiometer (SMMR) (Njoku et al., 1980) and the Special Sensor Microwave/Imager (SSM/I) (Colton and Poe, 1999), have provided passive microwave measurements of the earth surface since 1978. However, most of these satellites had local overpass times near 6:00 to 9:00 AM/PM. So they miss the daily maximum and minimum physical temperatures. In 2002, the Advanced Microwave Scanning Radiometer-Earth Observing System (AMSR-E) sensor on NASA's Aqua satellite was launched into an orbit with overpass times at 1:30 A.M./P.M. local solar time (Njoku et al., 2003). When combined with operational SSM/I instruments, better diurnal resolution can be obtained.

There are very few studies that have dealt with the characterization of the $T b$ diurnal variation over land. The diurnal variation of physical and brightness temperatures as a function of incident solar radiation has been modeled for the Tropical Rainfall Measuring Mission (TRMM) Microwave Imager (TMI) (Stephen et al., 2010). The characteristics of the skin temperature diurnal cycles as measured from IR over different land types were investigated using the Principal Component Analysis (PCA) approach applied to results from the International Satellite Cloud Climatology Project (ISCCP) (Aires et al., 2004). They found that the first three components represent the diurnal amplitude, the phase, and the seasonally and latitudinally varying daytime duration of the diurnal variation. In densely vegetated areas with more moisture, skin temperature exhibits a smaller diurnal variation than in arid and desert areas (Aires et al., 2004).

Our study builds on previous findings to develop a procedure to reduce globally the day-night discrepancies in land emissivity estimates for each overpass. First, the physical model proposed by Prigent et al (1999) is used globally to investigate the spatial variability of the penetration depth at different microwave frequencies. Secondly, we test another approach based on directly observed $T b$ diurnal variations to account for the discrepancies between day and night emissivity estimates. The $T b$ diurnal variation is constructed using $T b$ observed at different local times in similar channels of AMSR-E and SSM/I on multiple satellites. PCA is used to represent the spatial variation of microwave $T b$ diurnal cycles. A lookup table of effective temperature, $T_{\text {eff, }}$ anomalies (i.e. a temperature that represents the vertical integration of microwave emissions over a profile of layer temperatures) diurnal variation for each frequency and month is constructed from the PCA results. These $T_{\text {eff }}$ anomalies are used to reduce the differences between day and night estimates of land surface emissivity. Revised emissivities are estimated using the proposed lookup table.

\section{Data sets}

The AMSR-E L2A product (swath data) is obtained from National Snow and Ice Data Center (NSIDC). Data are originally resampled to be spatially consistent, and therefore are available at a variety of resolutions that correspond to the footprint sizes of the observations such as $56 \mathrm{~km}, 38 \mathrm{~km}, 24 \mathrm{~km}, 21 \mathrm{~km}, 12 \mathrm{~km}$, and $5.4 \mathrm{~km}$, for $6.925,10.65,18.7$, $23.8,36.5$, and $89.0 \mathrm{GHz}$ respectively. Each swath is packaged with associated geolocation fields. For each frequency, we selected the resampled data having the closest spatial resolution to the original footprint at that frequency. In this study, all data sets are re-projected to an equal area grid $\left(0.25^{\circ}\right.$ at equator $)$. At this type of projection, the area of the map grid cells is maintained equal with latitude by adjusting the longitude interval based on a $0.25^{\circ}$ cell area at the equator. Also, SSM/I observations from F13, F14, and F15 United States Air Force Defense Meteorological Satellite Program (DMSP) satellites provided by Global Hydrology Resource Center (GHRC) are mapped to the same grid and used to construct the diurnal cycle. More information such as crossing times, channels, and viewing angles for SSM/I and AMSR-E sensors are provided in Table 1.

Satellite infrared-based products from the International Satellite Cloud Climatology Project (ISCCP) are used for surface skin temperatures and cloud cover. The ISCCP-DX version provides information on skin temperature and cloud coverage every $3 \mathrm{~h}$ since 1983 (Rossow and Schiffer, 1999) at a $\sim 30 \mathrm{~km}$ spatial resolution, based on merged observations from geostationary and polar-orbiting satellites. ISCCP products were resampled to match the $0.25^{\circ}$ equal area grid adopted for the passive microwave observations. This skin temperature data set represents the top surface temperature; in the case of dense vegetation it may represent the top of the canopy.

Table 1

SSM/I and AMSR-E sensors information.

\begin{tabular}{|c|c|c|c|c|c|c|c|}
\hline Sensor & Satellite & $\begin{array}{l}\text { Temporal } \\
\text { coverage }\end{array}$ & Equator crossing time (2005) & Channels (GHz) & Polarization & Spatial resolution $(\mathrm{km})$ & Incidence angle \\
\hline \multirow[t]{4}{*}{$\mathrm{SSM} / \mathrm{I}$} & F13 & May 1995-present & 6:30 A.M./P.M. & 19.35 & $\mathrm{~V}, \mathrm{H}$ & $69 \times 43$ & $53^{\circ}$ \\
\hline & F14 & May 1997-Aug 2008 & 7:00 A.M./P.M. & 22.235 & V Only & $60 \times 40$ & \\
\hline & F15 & Jan. 2000-present & 9:00 A.M./P.M. & 37.0 & $\mathrm{~V}$ & $37 \times 28$ & \\
\hline & & & & 85.5 & V & $15 \times 13$ & \\
\hline \multirow[t]{6}{*}{ AMSR-E } & Aqua & Jun. 2002-present & 1:30 A.M./P.M. & 6.925 & $\mathrm{~V}, \mathrm{H}$ & $75 \times 43$ & $55^{\circ}$ \\
\hline & & & & 10.65 & $\mathrm{~V}, \mathrm{H}$ & $51 \times 29$ & \\
\hline & & & & 18.7 & $\mathrm{~V}, \mathrm{H}$ & $27 \times 16$ & \\
\hline & & & & 23.8 & $\mathrm{~V}, \mathrm{H}$ & $32 \times 18$ & \\
\hline & & & & 36.5 & $\mathrm{~V}, \mathrm{H}$ & $14 \times 8$ & \\
\hline & & & & 89.0 & $\mathrm{~V}, \mathrm{H}$ & $6 \times 4$ & \\
\hline
\end{tabular}


The TIROS Operational Vertical Sounder (TOVS) dataset available with ISCCP (Rossow and Schiffer, 1991) provides global information on air temperature and water vapor profiles at 9 vertical layers ranging from 900 to $15 \mathrm{mb}$ pressure. These profiles are available on a daily basis. Data are originally available in $280 \mathrm{~km}$ equal area map resolution. These atmospheric parameters are used to calculate the upwelling, down-welling brightness temperatures, as well as the atmospheric transmission.

\section{Statement of the problem}

The land surface $T b$ after removing the effect of the atmosphere can be written as:

$T b_{(p, v)}=\varepsilon_{e f f_{(p, v)}} \cdot T_{e f f}$

where $\varepsilon_{\text {eff }}$ and $T b_{(p, v)}$ are the land surface emissivity and the brightness temperatures (at the surface) at polarization $p$ and frequency $v$, respectively. $T_{\text {eff }}$ is the effective physical temperature (we refer to it as effective because it may represent an integration over a layer with varying temperature). Emissivity is a physical parameter, which depends on the characteristics, such as moisture, vegetation, surface roughness, and dielectric constant, as well as the sensor configuration (i.e. viewing angle and frequency). Therefore, $T b$ variation should be similar to the $T_{\text {eff }}$ variation for stable surface conditions. In other words, we expect that the physical and brightness temperatures should vary more rapidly than the surface properties represented by the emissivities. The exceptions are produced by some land surface variations due to precipitation, soil moisture, dew deposition over vegetated areas, and accumulation of snow. For instance, previous studies have shown that emissivities at low frequencies such as 1.4 and $2.65 \mathrm{GHz}$ could have a correspondence with soil moisture diurnal cycle (Jackson et al., 1997).

In our previous study (Norouzi et al., 2011), we estimated microwave land surface emissivities over the globe from AMSR-E observations at all frequencies and both polarizations. The effects of the atmosphere were removed using the TOVS atmospheric temperature - humidity dataset available with ISCCP and an appropriate radiative transfer approximation (Liebe, 1989; Liebe et al., 1993). The ISCCP-DX product provided land surface skin temperature and cloud mask.

The previous emissivity retrieval is based on the assumption that the infrared skin temperature is the effective physical temperature, which is equivalent to assuming that the microwave brightness temperature originates from the skin. This assumption is not necessarily true, but necessary because of a lack of general global information on penetration depth and temperature profile. One measure of the accuracy of this assumption is provided by the differences of the retrieved emissivities between ascending and descending (day/night) orbits (Fig. 1). The largest differences (more than $4 \%$ ) are found in more arid and less vegetated regions even though we expect smaller differences because of small moisture changes from day to night. The 6.9 and $89.0 \mathrm{GHz}$ frequencies both have the same spatial pattern of differences; but the emissivity difference between day and night at $89.0 \mathrm{GHz}$ is noticeably smaller than at $6.9 \mathrm{GHz}$ at the same locations due to its smaller penetration depth (Fig. 1).

A physical model was proposed (Prigent et al., 1999) to account for the effect of penetration depth on emissivity retrievals by revising the physical temperature. This method is based on one-dimensional heat transfer by conduction and was tested over North Africa, the Saudi Arabian desert, and Australia. We implemented this model globally to analyze the spatial variation of the penetration depth at different frequencies and polarizations. The model calculates the temperature diurnal cycle for a given depth and time of the day using the first two terms of the Fourier solution as follows:

$T(d, t)=T_{0}+\sum_{n} A_{n} \exp \left(-d \sqrt{\frac{n \omega_{0}}{2 \kappa}}\right) \cos \left(n \omega_{0} t+\phi_{n}-d \sqrt{\frac{n \omega_{0}}{2 \kappa}}\right)$
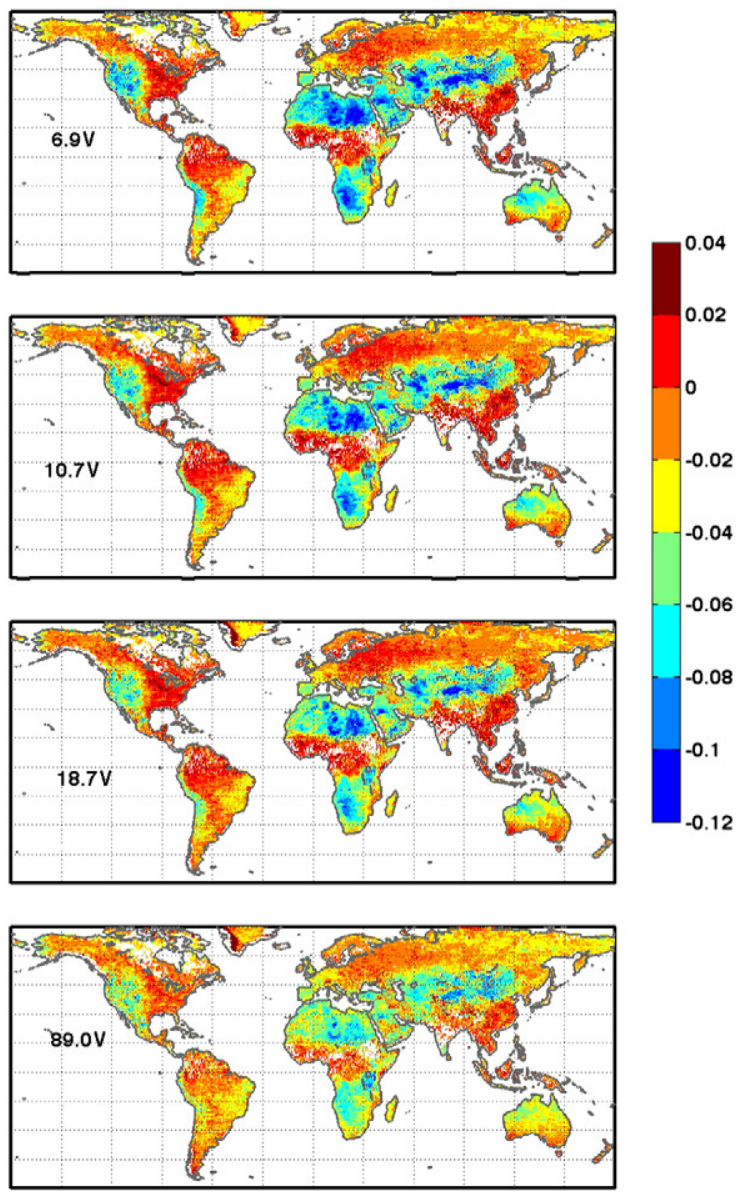

Fig. 1. Difference between ascending and descending monthly averages of AMSR-E emissivities at 6.9, 10.7, 18.7, and 89.0 GHz (vertical polarization) for July 2003.

$T(d, t)$ is the temperature at depth, $d$, and time $t . T_{0}, A_{n}$, and $\phi_{n}$ are the coefficients of the Fourier solution. $\kappa$ is the thermal diffusivity and $\omega_{0}=\frac{2 \pi}{3600 \times 24} \mathrm{rad} / \mathrm{sec}$ is the angular frequency for a period of $24 \mathrm{~h}$. $\alpha=d \sqrt{\frac{\omega_{0}}{2 \kappa}}$ is proportional to the penetration depth, $d$.

The surface skin temperature variation as a boundary condition can be used to determine $T_{0}, A_{n}$, and $\phi_{n}$ by setting $d=0$ in Eq. (2) and using a nonlinear least square solution:

$T(0, t)=T_{0}+\sum_{n} A_{n} \cos \left(n \omega_{0} t+\phi_{n}\right)$

Similar to Prigent et al. (1999), the emissivity and $\alpha$ were then estimated on a monthly basis by minimizing the differences between measured and simulated $\mathrm{Tb}$ over a month. AMSR-E microwave observations at different channels along with the corresponding upwelling and downwelling temperature and atmospheric transmission throughout a given month were used. The root mean square (RMS) errors of the fit amongst all AMSR-E channels vary between $3.6 \mathrm{~K}$ and $4.5 \mathrm{~K}$ at the global scale.

Global maps of $\alpha$ obtained for July 2003 at 6.9, 18.7, 36.5, and $89.0 \mathrm{GHz}$ (vertical polarization) are shown in Fig. 2. As expected, the value of $\alpha$ as an indicator of the penetration depth is larger in arid and semi-arid regions (more than 0.4). For instance, large alpha values are found in the Sahara desert, Middle East, South Africa, and Western United States. These regions also correspond to regions with larger emissivity differences between day and night found in our previous analysis (Fig. 1). This correspondence is confirmed by Fig. 3, which shows that as the alpha increases the day-night differences of retrieved emissivities increase as well. The few points with large alpha and small differences between day and night are found 


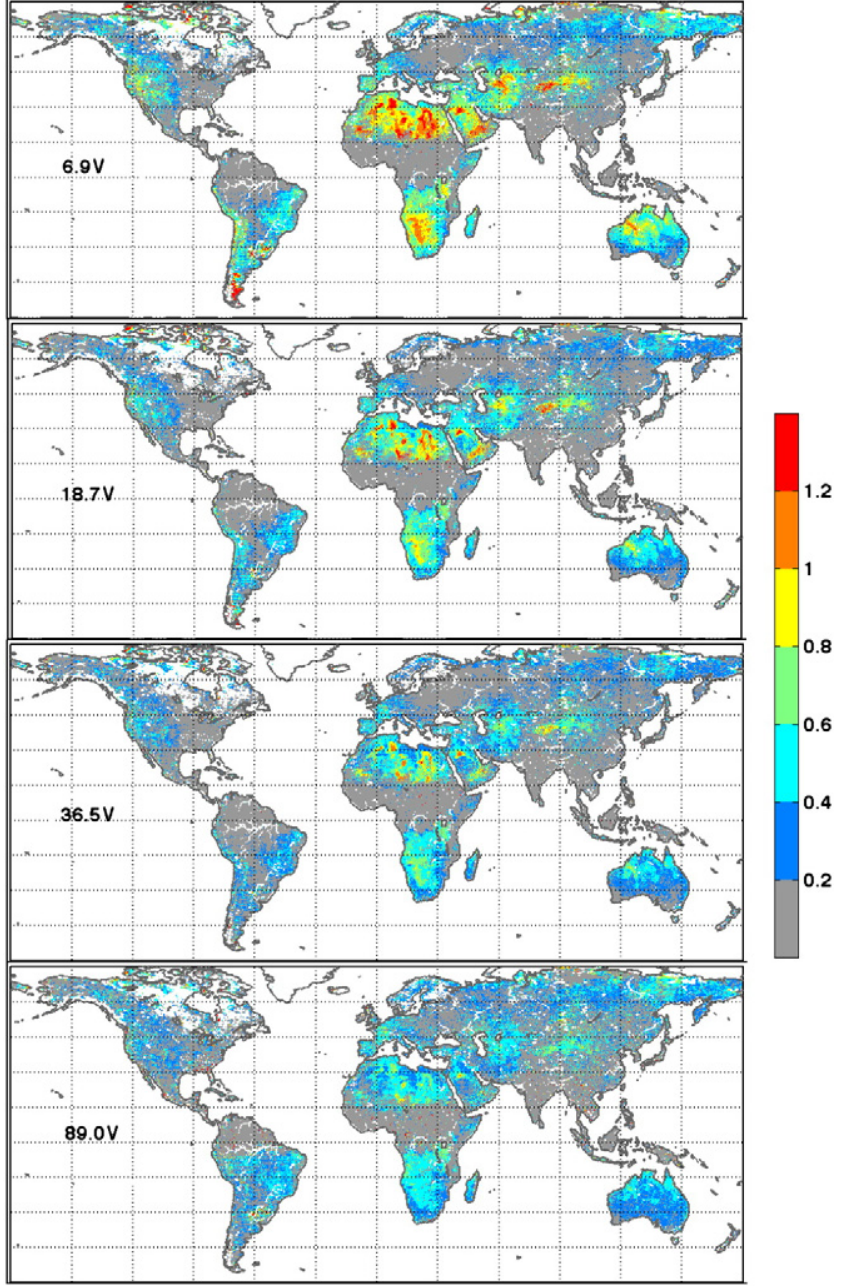

Fig. 2. Global map of $\alpha=d_{e f f} \sqrt{\frac{\omega_{0}}{2 K}}$ at $6.9,18.7,36.5$, and $89.0 \mathrm{GHz}$ (vertical polarization) from physical model for July 2003.

to be in the coastal, snow and ice regions. Regions with larger alpha values (more than 0.4 ) tend to be dryer than densely vegetated areas such as Amazon, Congo, and Eastern United States (Fig. 2). Water (in moist areas) reduces the penetration depth (Njoku and Entekhabi, 1996) and the diurnal temperature variations. In North Africa and Saudi Arabia the pattern of the alpha map is consistent with available previous studies maps in these regions by Prigent et al (1999). Also as expected, the penetration depth decreases with frequency; for instance the alpha values decrease in North Africa with frequency (Fig. 2).

The variability of the determined alpha parameter with frequencies and polarization can be seen using the scatter plots as in Fig. 4. The figure shows the relation between alpha at $6.9 \mathrm{~V}$ versus alpha at $6.9 \mathrm{H}, 18.7 \mathrm{~V}, 36.5 \mathrm{~V}$, and $89.0 \mathrm{~V}$. The microwave $\mathrm{Tb}$ originate from the same depth at a given frequency even if the polarization is different, as illustrated in the scatter plot of alphas between 6.9 vertical and horizontal polarizations. However, as frequency increases the alpha parameter or the penetration depth decreases. This corroborates and expands to a global scale the previous findings by Prigent et al (1999) which were based on a regional study.

The described physical model is applied on a monthly basis; however instantaneous emissivity retrievals that account for the effect of penetration depth are not possible using this approach, as it uses statistical fit to all observations over a month to estimate the emissivity and penetration depth. One solution for this problem could be to use climatology of alpha and then estimate the instantaneous emissivity. However, we propose an adaptive alternative approach that directly uses the $T b$ diurnal variations at multiple frequencies. Nowadays

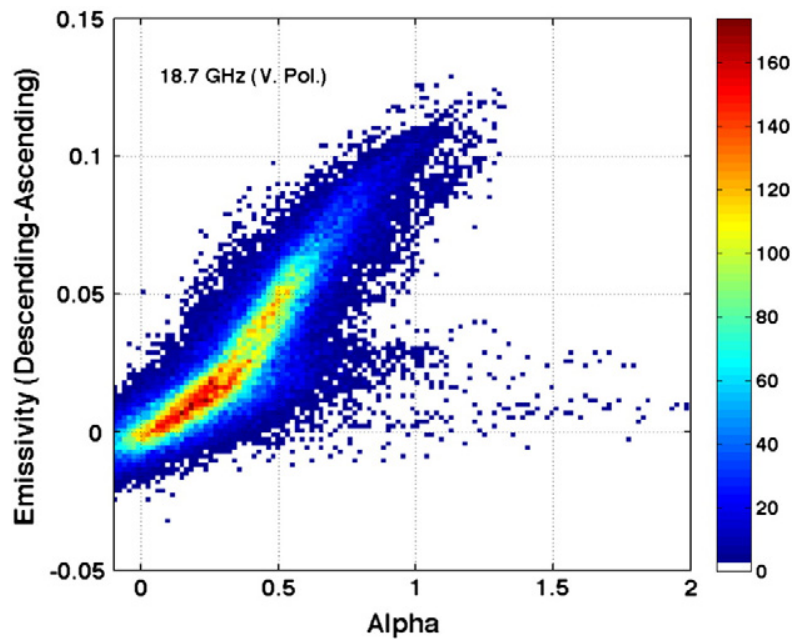

Fig. 3. $\alpha$ versus descending and ascending emissivity differences at $18.7 \mathrm{~V}$ for July 2003. Color bar represents number of pixels.

there are more sensors available with different orbit times-of-day, such as the combination of AMSR-E and SSM/I. In particular, the addition of AMSR-E to the constellation provides observations nearer to the daily maximum and minimum temperature, which improves the construction of the diurnal variations. The following sections present the

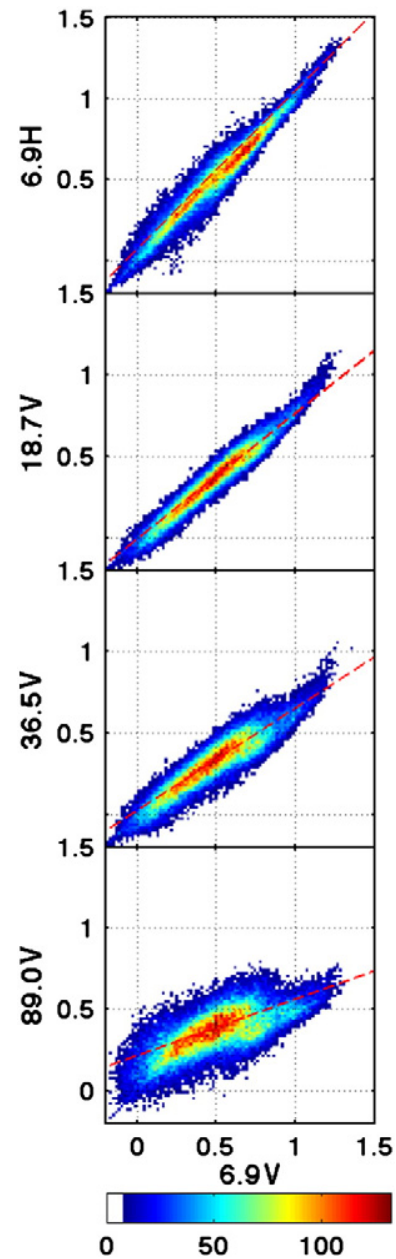

Fig. 4. Scatter plots of $\alpha=d_{\text {eff }} \sqrt{\frac{\omega_{0}}{2 \kappa}}$ at $6.9 \mathrm{~V}$ versus $6.9 \mathrm{H}, 18.7 \mathrm{~V}, 36.5 \mathrm{~V}$, and $89.0 \mathrm{~V}$ for July 2003. Color bar represents number of pixels. 
proposed method and demonstrate its ability to reduce the discrepancies between ascending and descending emissivity retrievals.

\section{Methodology}

\subsection{Diurnal cycle of microwave brightness temperature}

Passive microwave observations from AMSR-E onboard Aqua and observations from SSM/I sensor from F13, F14, and F15 DMSP satellites are utilized to construct the mean diurnal cycle. TMI sensor also may sound helpful in determining the $T b$ diurnal variation construction. However, the TMI overpass time drifts through the diurnal cycle very slowly, which means that the sample size at each time of the day in a month is very small and its spatial coverage is limited to $38 \mathrm{~N}$ and $38 \mathrm{~S}$ latitudes. Moreover, TMI was shown to have some diurnal biases when compared to other conical sensors such as AMSR-E and SSM/I due to solar heating of its main reflector (Geer et al., 2010). Only AMSR-E channels, which are similar to SSM/I channels $(19,22$, 37 , and $89 \mathrm{GHz}$ ), are used. The particular differences in incidence angle and frequency do not induce any substantial differences in $T b$ from AMSR-E and SSM/I (Norouzi et al., 2011).

Using ascending and descending overpasses from the three DMSP satellites (F13, F14, and F15) and Aqua provides eight observations per day. The local solar time of observation at each location for all satellites is almost constant within a month (sun-synchronous orbits), but DMSP satellites have more variable crossing times than AMSR-E. The crossing time of each SSM/I observation is used. Only cloud free observations are used which reduces the spatial coverage on a given day and produces time gaps. Although microwave observations especially at lower frequencies are less sensitive to cloud, for consistency reasons a restrictive cloud mask, which includes rainy and cloudy pixels, was used. The cloud mask, which is part of the ISCCP data set, was used to detect cloudy pixels. In addition, gaps between consecutive orbit swaths constitute a further loss of data, which reduces the chance for obtaining 8 clear sky microwave observations per day (less than $10 \%$ globally). Therefore, the average of the cloud free observations for each crossing time in a month is used to determine the shape of the monthly mean diurnal cycle at each location. This typical monthly mean diurnal cycle may still have some contamination by synoptic variability. Fig. 5 shows the monthly mean $\mathrm{Tb}$ diurnal cycle at 19 and $37 \mathrm{GHz}$ using a Spline interpolation and a 4th degree best fit over North Africa and Amazon. $37 \mathrm{GHz}$ has larger amplitude because of its smaller penetration depth. The amplitudes at both frequencies are larger in North Africa with desert land cover type than in the Amazon with more surface moisture. The best fit exhibits a smoother diurnal variation, which reduces contamination by synoptic variations as well as variations due to calibration (a)

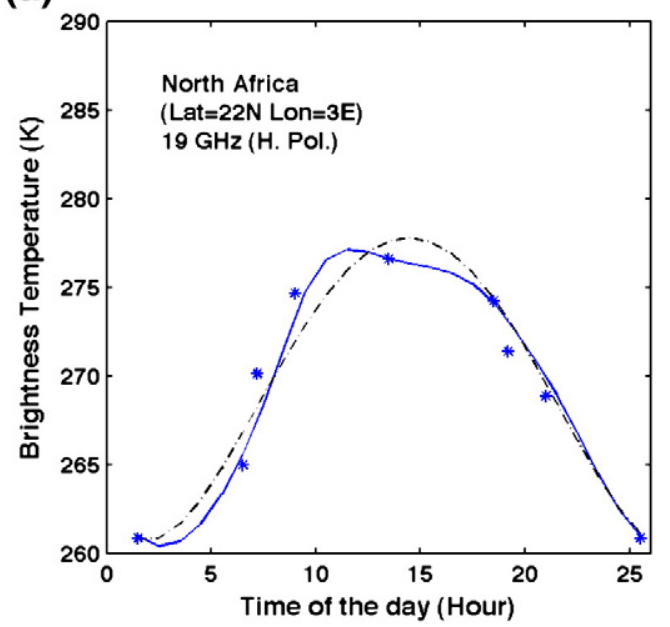

(c)

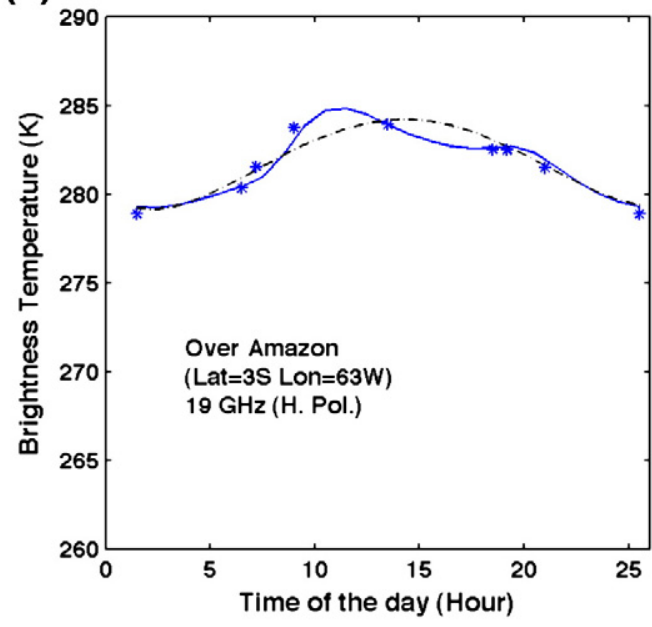

(b)

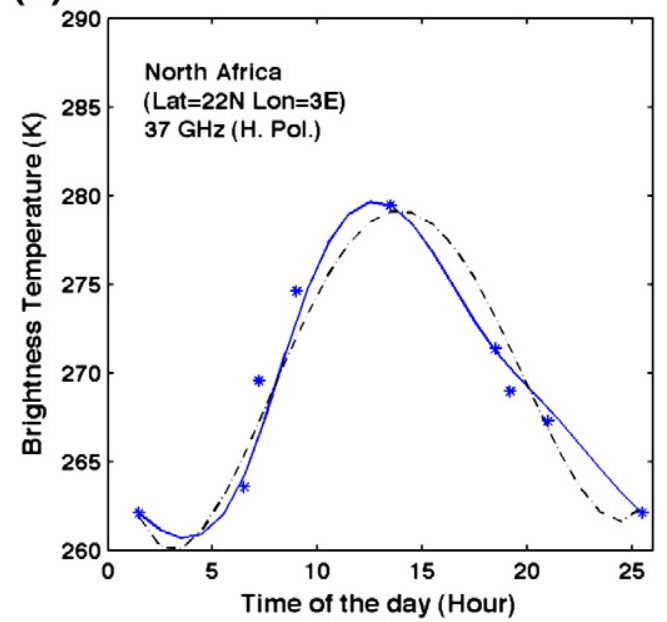

(d)

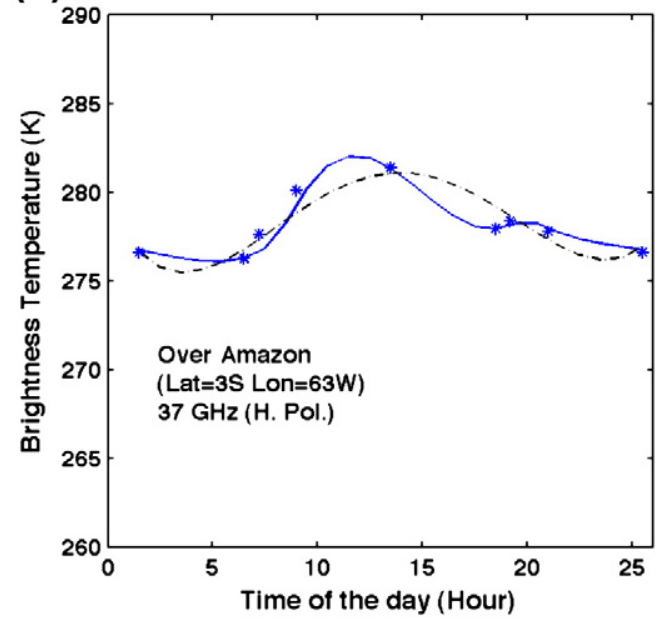

- Spline ----4th Best fit $\quad *$ Observations

Fig. 5. (a, b) Tb diurnal cycle at $19 \mathrm{H}$ and $37 \mathrm{H}$ using observations, Spline interpolation, and 4th degree best fit for July 2003 over North Africa (c, d) the same over Amazon. 
differences, re-projection, and small differences of sensors configuration. Therefore, we use the best fit interpolated to an hourly interval at each pixel for each month and each channel.

\subsection{Principal component analysis}

A principal component analysis (Jolliffe, 2002) is used to assess the spatial variability of $T b$ diurnal cycles at different frequencies over land. PCA is applied globally to the monthly average $T b$ diurnal cycles using the best-fit interpolation to 24 hourly values. Only pixels with a complete diurnal cycle are considered. Brightness temperatures at $19 \mathrm{~V}, 19 \mathrm{H}, 23 \mathrm{~V}, 37 \mathrm{~V}, 37 \mathrm{H}, 89 \mathrm{~V}$, and $89 \mathrm{H}$ are analyzed separately. The mean diurnal cycle of the temperature is subtracted at each pixel (i.e. the data are centered) and PCA is performed on the anomalies, otherwise the first component would be geographic variation of the monthly mean temperature.

The first three components explain more than $98 \%$ of the variability, between 70 and $80 \%$ by the first component and $15-25 \%$ and 3-6\% by the second and the third components, respectively, at different channels.

The eigenvectors of the first three PCA components are very similar to those obtained for the infrared skin temperatures (Aires et al., 2004), but the order of second and the third eigenvectors is reversed. To investigate the effect of each component on the shape of the diurnal cycle, a sensitivity analysis was conducted by applying a variety of scores for each component. The first two components affect the amplitude of the diurnal cycle. Also, the second component was found to affect the duration of the daytime part of the diurnal cycle. The third component represents mostly the change in phase or the timing of the maximum and minimum temperatures.

The geographic variation of each component eigenvalue (score) is shown in Fig. 6. For the first component, large positive numbers increase the diurnal amplitude and negative values decrease it. The spatial variation of the first component clearly shows land cover/moisture/vegetation influences on the diurnal cycle amplitude (Fig. 6 top). Desert regions, such as North Africa, Middle East, and Australia show large positive eigenvalues. On the other hand, more densely vegetated areas, such as Amazon and Congo, show small scores with negative signs. However, in desert areas there are some regions that show opposite signs. These regions are sand dunes in Sahara desert that have small $T b$ diurnal variation (Grody and Weng, 2008; Prigent et al., 1999). The microwave results in these regions contrast with skin temperature diurnal variation in deserts that have large amplitudes everywhere (Aires et al., 2004).

The second PCA component affects both the diurnal amplitude and the duration of the daytime portion. The combination of these two characteristics in Fig. 6 (middle) exhibits noticeable differences with latitude and land cover. The second component has larger values as latitude increases to account for more seasonal variation in length of day. The last map in Fig. 6 (bottom) displays values of the third component that reflect the phase of the diurnal cycle. The largest phase difference relative to the global mean diurnal cycle appears in arid and semi-arid regions, where the soil wetness is much smaller than in moderately vegetated areas. Some places in the North African deserts with large phase lag are associated with sand dunes or loose siliceous rocks, when they are compared with the geological characteristics of the region (Jimenez et al., 2010) (not shown).

\subsection{Generating diurnal effective temperature anomalies lookup table}

The diurnal variations of infrared and microwave brightness temperatures are investigated at a variety of different locations, selected to illustrate various differences between day and night emissivities. A location with a small day-night emissivity difference (Fig. 7a) in a densely vegetated area in the East European Plain (Lat $=60 \mathrm{~N}$, Lon $=30 \mathrm{E}$ ) and one with large differences (Fig. 7d) in the Sahara desert in North Africa (Lat $=25 \mathrm{~N}$, Lon $=12.5 \mathrm{E}$ ) with sand dunes were selected. Two other
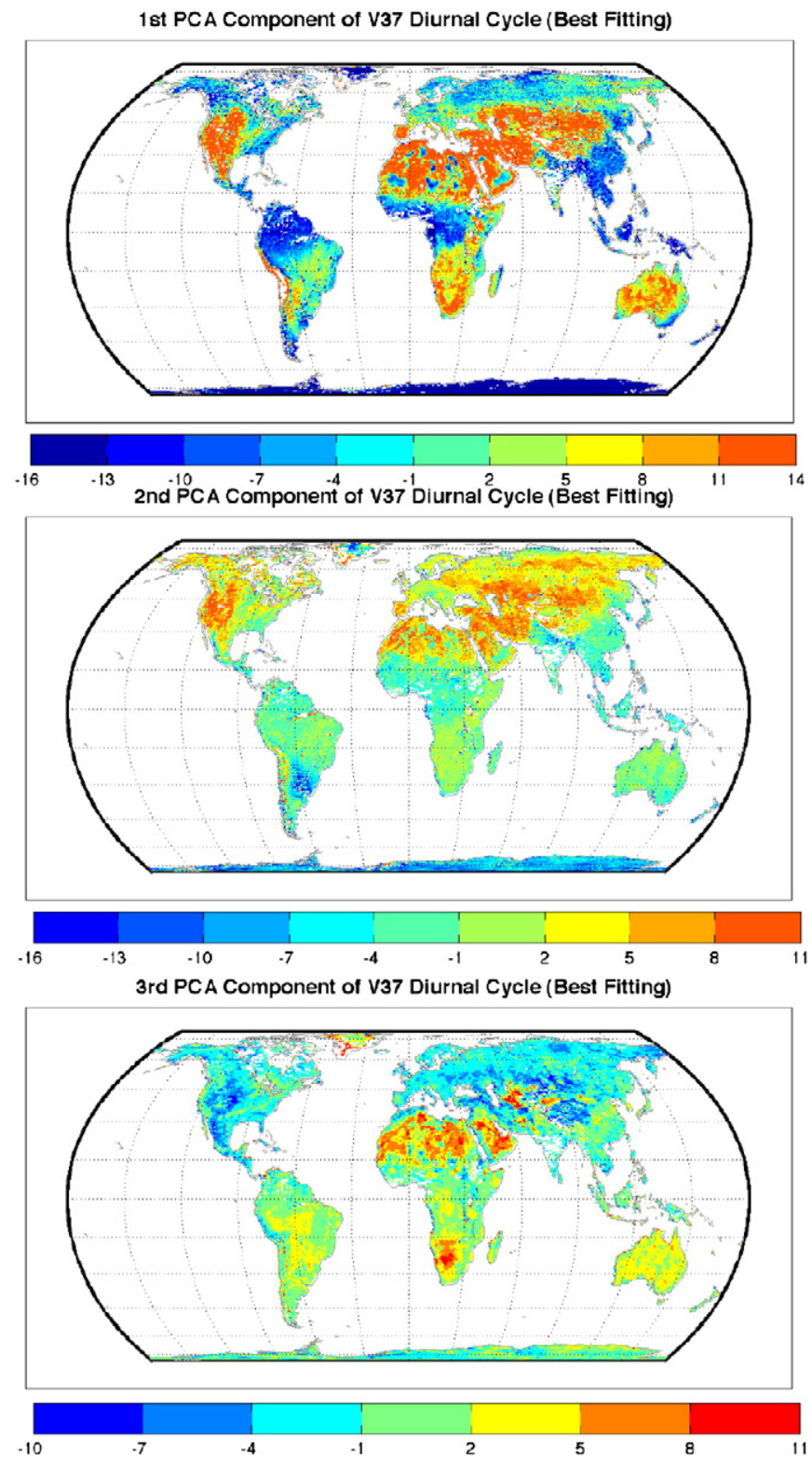

Fig. 6. Map of the spatial variation of the first three PCA components scores (eigenvalues) at $37 \mathrm{~V}$ for July 2005.

locations with intermediate emissivity differences are also depicted (Fig. 7b-c). The Spline-interpolated ISCCP-DX diurnal cycle of the infrared skin temperature is shown for each location along with the Tb diurnal cycles (best-fit model) at 19, 37, and $89 \mathrm{GHz}$ for vertical polarization from AMSR-E and SSM/I observations. The Spline method was chosen for ISCCP skin temperature as it showed smooth diurnal variation and there was no need for best-fit. The diurnal cycle of the skin temperature and microwave observations have similar amplitudes in the region with small differences between day and night retrieved emissivities (Fig. 7a). However, noticeable differences in amplitude between skin temperature and $T b$ appear in the other regions with larger day-night emissivity differences (Fig. 7c-d). One can notice that even $\mathrm{Tb}$ diurnal cycle at $89 \mathrm{GHz}$ with smaller penetration depth is also not consistent with skin temperature from IR. This may explain some overestimation of alpha values developed by Galantowicz et al (2011) (compared to this study and Prigent et al (1999)) when brightness temperatures at $89 \mathrm{GHz}$ were used to find the Fourier coefficients (Galantowicz et al., 2011). Moreover, the difference in amplitude and phase increases as 
(a)

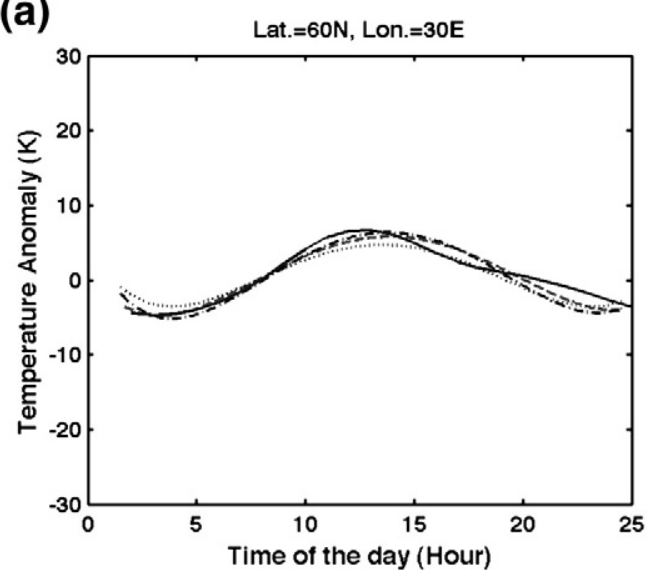

(c)

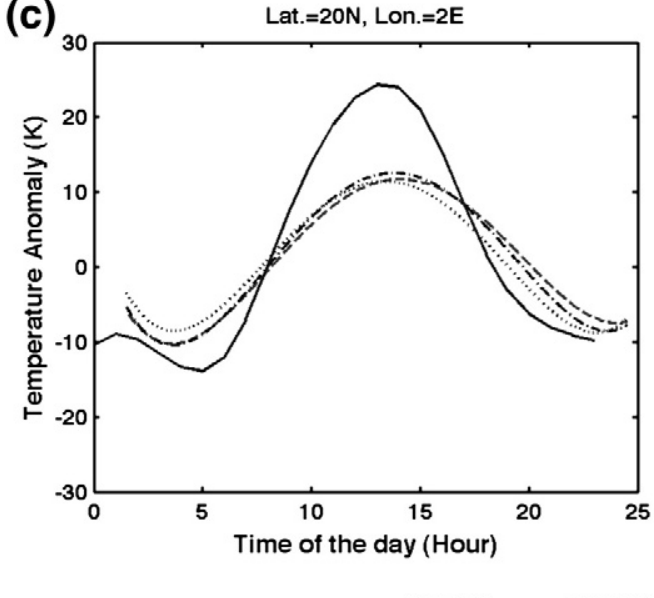

(b)

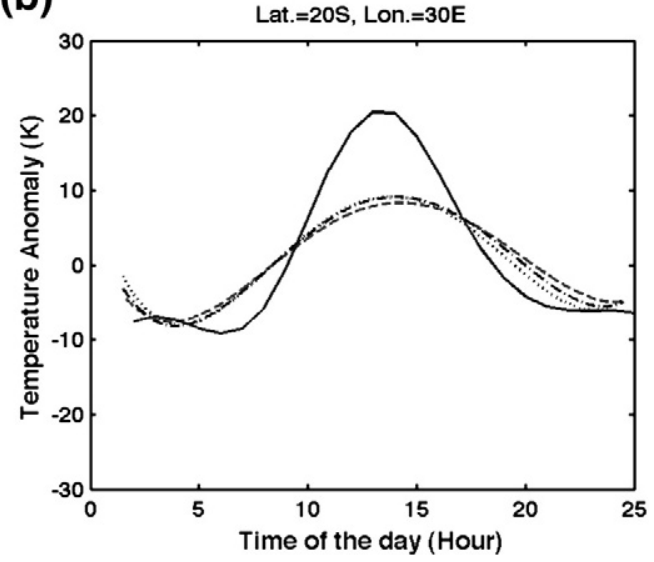

(d)

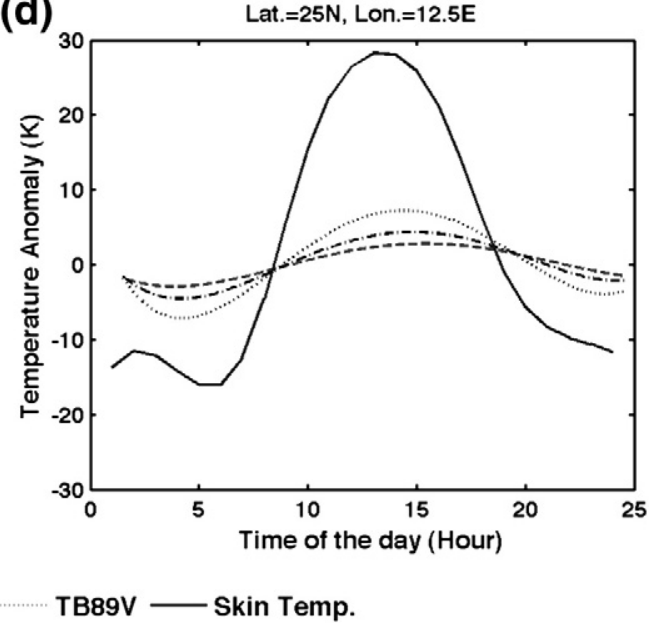

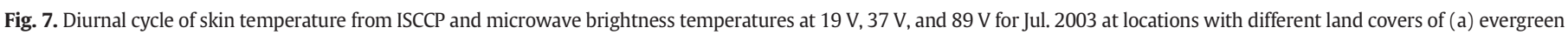
forest (b) woodland and cultivation (c) Sahara desert with rock (d) Sahara desert with sand dunes.

frequency decreases as expected. Fig. 8 depicts the diurnal variation of the retrieved emissivities at the same locations obtained using the skin temperature diurnal cycle in the retrieval. Fig. 8 shows that the emissivity has a small variation diurnally, when the differences between microwave and skin temperature amplitude are small, but the apparent diurnal variation of emissivity increases to as much or more than 0.1 , when the diurnal amplitude differences increase. We conclude that the apparent diurnal variation of emissivity is caused by the discrepancy between the infrared skin temperature used in the retrieval and $T_{\text {eff }}$ at deeper levels sensed by the microwave channels.

The monthly mean $\mathrm{Tb}$ can be written in a simplified equation by ignoring the effect of the atmosphere as follow:

$\overline{T b_{(p, v)}}=\overline{\varepsilon_{(p, v)} \cdot T_{e f f}}$

In other words, the monthly mean brightness temperature, $\overline{T b_{(p, v)}}$, is proportional to the monthly average of the product of emissivity and physical temperature, $\overline{\varepsilon_{(p, v)} \cdot T_{\text {eff }}}$. Since the emissivity should be nearly constant for a given frequency and incidence angle, if moisture and vegetation are not changing too rapidly (as confirmed by previous studies, showing that the global RMS of emissivity standard deviation within a month is less than 0.015 (Norouzi et al., 2011)), Eq. (4) can be rewritten as:

$T b_{(p, v)}^{*} \approx \overline{\varepsilon_{(p, v)}} \cdot T_{e f f}^{*}$ where $T b_{(p, v)}^{*}$ and $T_{\text {eff }}^{*}$ are the diurnal microwave and effective temperatures at a given time of the day. $\overline{\varepsilon_{(p, v)}}$ is monthly average of emissivity as a given frequency and polarization.

Finally, the $T_{\text {eff }}$ diurnal change from time $t_{1}$ and $t_{2}$ within a day is given by:

$T_{e f f 2}^{*}-T_{e f f 1}^{*}=\frac{T b_{(p, v)_{2}}^{*}-T b_{(p, v)_{1}}^{*}}{\overline{\varepsilon_{(p, v)}}}$

Therefore, the shape of $T_{\text {eff }}$ diurnal variation is proportional to the shape of $T b$ variation divided by the monthly averaged emissivity.

Based on the PCA analysis, the first three components explain almost 98 percent of the Tb variability. We use the first three PCA components divided by monthly averaged emissivity to reconstruct the $T_{\text {eff }}$ diurnal variations at each frequency and polarization. For emissivity, $\overline{\varepsilon_{(p, v)}}$, we use the previously determined monthly mean emissivities (Norouzi et al., 2011). According to the physical model, the effective temperatures oscillate diurnally about the daily average of the skin temperature (Grody and Weng, 2008; Prigent et al., 1999). The reason is that the temperature tends toward equilibrium according to the heat transfer model. This is confirmed when we tested for the time (based on a model calculation) that it takes to have constant temperature at deeper layer with a constant source of heat. The maximum time that is needed to reach this equilibrium was found to be less than a day, around $17 \mathrm{~h}$. Therefore, the final formula for $T_{\text {eff }}$ can be written as:

$T_{\text {eff }}=T_{\text {Smean }}+T B_{P C A_{\cdot(p, v)}} / \varepsilon_{(p, \nu)}$ 
(a)

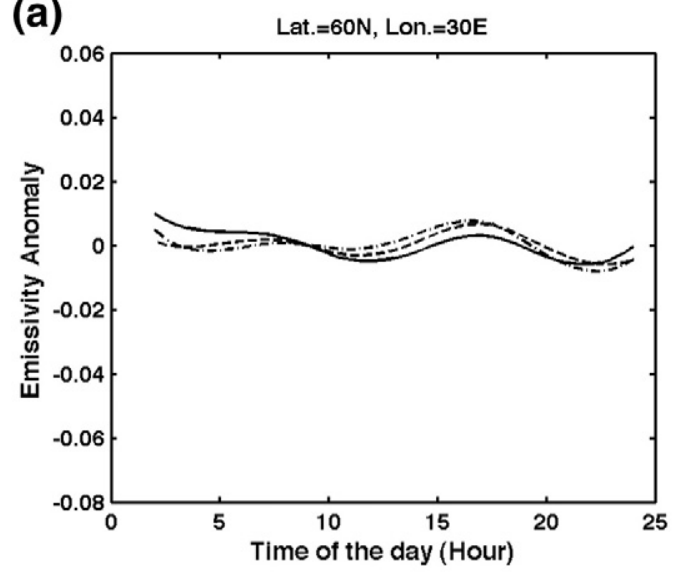

(c)

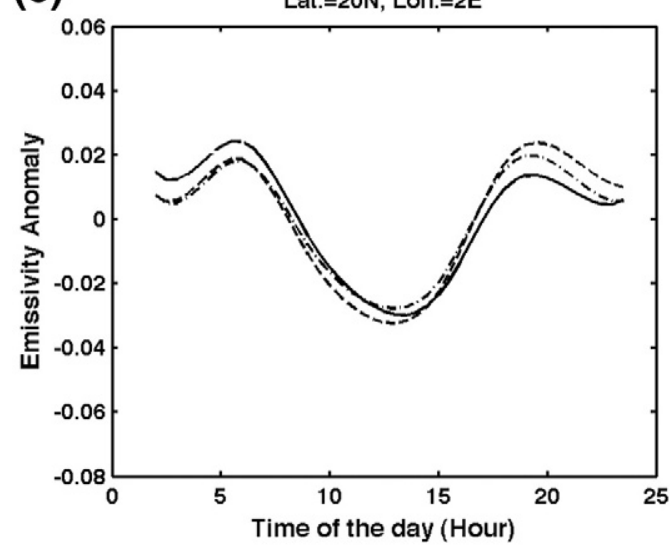

(b)

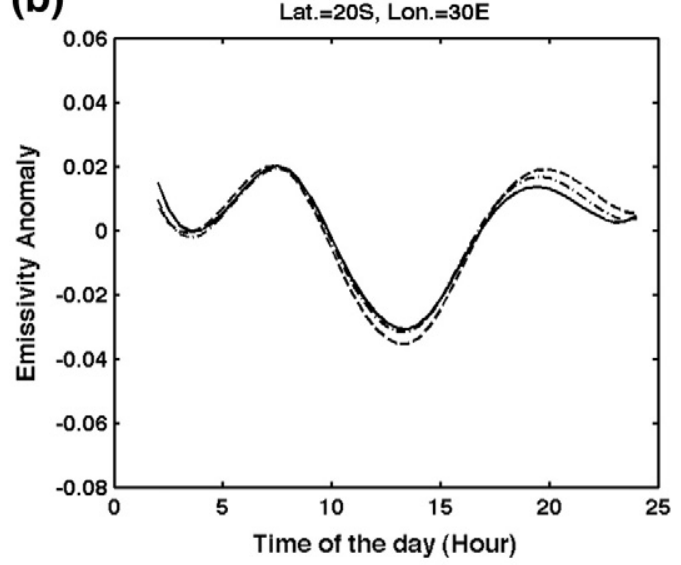

(d)

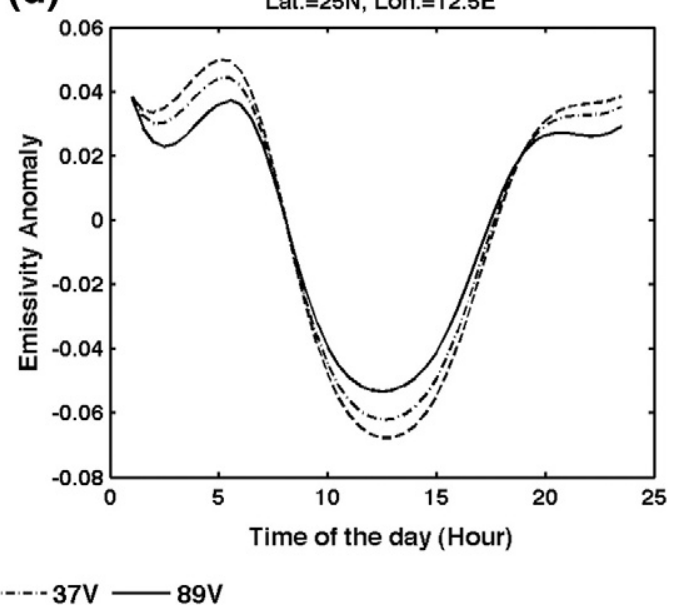

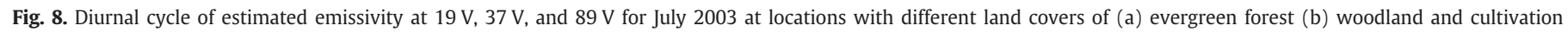
(c) Sahara desert with rock (d) Sahara desert with sand dunes.

$T B_{P C A_{(p, v)}}$ is the PCA-reconstructed $T b$ diurnal cycle (anomalies) and $T_{\text {Smean }}$ is daily average of the skin temperature which may vary day to day, however the variation of the second term is not significant, as it is centered about zero. We keep the second term for each channel and each month of the year as a lookup table of $T_{\text {eff }}$ diurnal cycle anomalies. This lookup table can be used to estimate $T_{\text {eff }}$ simply by adding the average of the skin temperature. The revised temperature, instead of skin temperature, is then used to retrieve emissivity instantaneously according to the previously implemented methodology (Norouzi et al., 2011; Prigent et al., 1997, 1998). The proposed approach is therefore adaptive as it accounts for daily variability of skin temperature and determines the equivalent $T_{\text {eff }}$ accordingly.

\section{Results and discussion}

Fig. 9 shows some examples of the centered diurnal effective temperature (anomalies) lookup table at 18.7 and $36.5 \mathrm{GHz}$ (vertical polarization) for four different locations based on the described methodology. It illustrates the different diurnal variations at different locations for different seasons of the year. At a location with sand dunes according to Jimenez et al. (2010) (Fig. 9 middle), both frequencies show very small diurnal amplitude with small monthly change. However, in other regions larger diurnal amplitudes and larger differences of the monthly diurnal shapes are seen. The difference in diurnal amplitudes for different months can be more than $10 \mathrm{~K}$ at this location (Fig. 9 bottom). Generally, $37 \mathrm{~V}$ (Fig. 9 right column) shows larger amplitude than $19 \mathrm{~V}$ (left column), as $37 \mathrm{GHz}$ is less sensitive than $19 \mathrm{~V}$ to the subsurface and originates from a depth closer to the surface. This confirms that $19 \mathrm{~V}$ or lower frequencies with larger alpha and penetration depth have smaller diurnal variations than higher frequencies (Prigent et al., 1999).

The developed lookup table of $T_{\text {eff }}$ diurnal cycles anomalies is then examined to see if the diurnal cycle shapes are stable enough to be used in other years as a consistent representation of the diurnal cycle. Deseasonalized anomalies of the amplitude of $T_{\text {eff }}$ are examined (Fig. 10) for different land cover types adopted by Prigent et al (Prigent et al., 2001) from (Matthews, 1983). For all considered land cover types (rain forests, deciduous woodland, and desert areas), the anomalies are mostly between -1 and $1 \mathrm{~K}$ with a standard deviation of $0.4 \mathrm{~K}$. Similar small anomalies were found for all other land types (not shown). This shows that the year-to-year variation of diurnal temperature amplitude is small, so $T_{\text {eff }}$ diurnal cycle anomalies tables for each month can be used for other years.

The instantaneous emissivities at different AMSR-E frequencies for each ascending and descending observation are estimated using the proposed $T_{\text {eff }}$ diurnal cycle anomalies lookup table. First, the anomaly of the $T_{\text {eff }}$ diurnal variation at AMSR-E overpass time is extracted from the lookup table. Then, the anomaly is added to the daily mean skin temperature according to Eq. (7) and estimated $T_{\text {eff }}$ is used in our emissivity retrieval. The monthly mean composite maps of new emissivities are estimated by averaging over the retrieved instantaneous emissivities for both ascending and descending. Note that only the frequencies higher than or equal to $18.7 \mathrm{GHz}$ are used in this method, as the $T_{\text {eff }}$ anomalies are only available for common channels between 


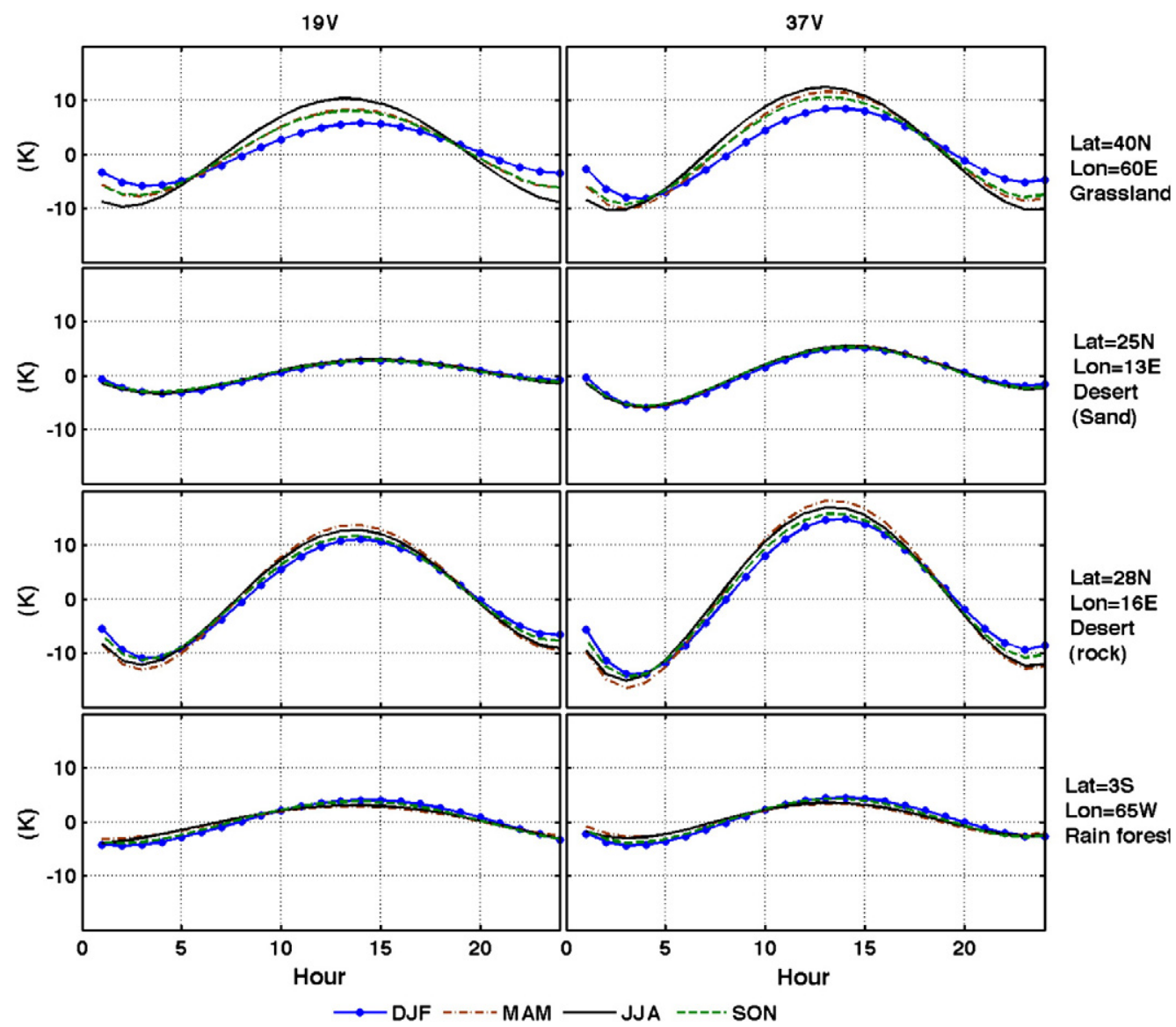

Fig. 9. Lookup table of $T_{\text {eff }}$ diurnal cycle anomalies at $19 \mathrm{~V}$ (left) and $37 \mathrm{~V}$ (right) at different locations and seasons.

AMSR-E and SSM/I. Fig. 11 shows the monthly mean composite of emissivity at $18.7,36.5$, and $89.0 \mathrm{GHz}$ (both vertical and horizontal polarizations) for July 2003. The general spatial patterns of the retrieved emissivities at different frequencies are similar to our previous retrievals (Norouzi et al., 2011). For instance, at horizontal polarization frequencies, deserts such as North Africa, West of US, and deserts in Australia show smaller emissivity values than more vegetated areas such as Amazon, Congo, and East of US. In vertical polarization, the
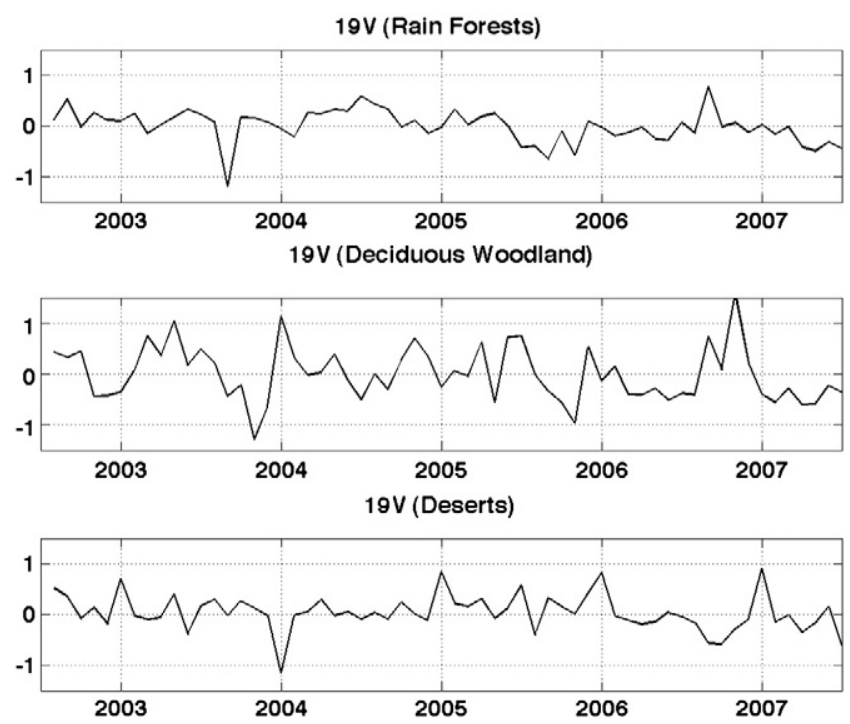

Fig. 10. De-seasonalized monthly mean (anomaly) of $T b$ diurnal amplitude at $19 \mathrm{~V}$ at rain forests, deciduous woodland, and desert regions. opposite contrast between deserts and vegetated area appears, as the deserts show greater emissivities at $18.7 \mathrm{GHz}$ than the vegetated area.

The main objective of this study is to mitigate the differences between day and night emissivities. Fig. 12 shows the map of the difference between ascending and descending emissivity maps for 18.7, 36.5 , and $89 \mathrm{GHz}$ (vertical polarization) before and after using the proposed $T_{\text {eff }}$ for July 2003 . Arid and semi-arid regions show up to 10 percent differences between day/night (ascending/descending) emissivities without adjusting $T_{\text {eff. }}$. The difference between day and night significantly decreases when the proposed lookup tables of $T_{\text {eff }}$ anomalies are used in the retrieval. Almost no systematic difference is noticed with the new method: differences are very small (mostly less than 0.01 ). However, the number of places with positive emissivity differences has increased without any systematic pattern. These residual sporadic differences increase with frequency suggest that they are caused by small atmospheric contamination in the retrieval.

Fig. 13 presents the normalized histogram of the differences of the newly estimated emissivities between ascending and descending observations with and without using the proposed $T_{\text {eff }}$ anomalies (Norouzi et al., 2011). The histograms show the differences at 18.7, 36.5 , and $89.0 \mathrm{GHz}$ (vertical polarization) for deserts and over the globe. At all frequencies, the differences between ascending and descending emissivities have been decreased significantly. The mean difference globally between ascending and descending is about -0.003 with standard deviation of 0.01 for July 2003 at $18.7 \mathrm{GHz}$ vertical polarization. The results in terms of global mean and standard deviation at different frequencies before and after applying the proposed method are summarized in Table 2. The global mean difference is reduced about 0.02 after using the proposed $T_{\text {eff }}$ diurnal cycle anomalies. In desert regions, there is an obvious improvement in reducing the differences of day and night emissivities. 


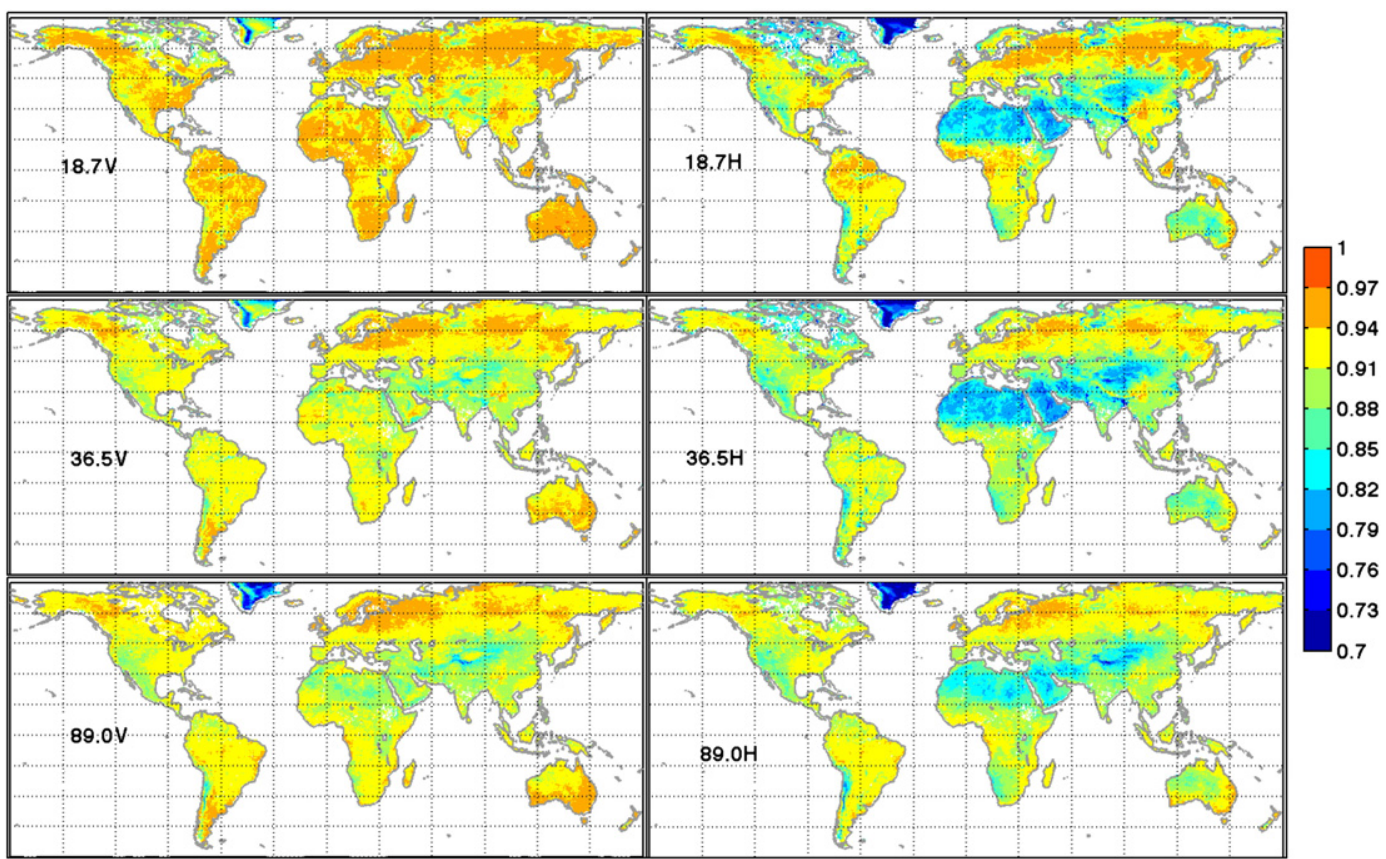

Fig. 11. Global monthly maps of emissivity at different channels using the proposed $T_{\text {eff }}$ diurnal cycles anomalies for July 2003.

The differences are slightly larger at $89 \mathrm{GHz}$ after applying the method (about 0.005 greater) compared to other channels. The reason could be because the effect of the atmosphere was neglected in Eq. (5) for generating the diurnal $T_{\text {eff }}$ anomalies lookup table. As the frequency increases, the sensitivity of emissivity to atmospheric variations increases (Prigent et al., 2008; Weng, 2007; Weng et al., 2001). Moreover, the atmospheric information (TOVS) used in the emissivity retrieval has only daily sampling so the diurnal cycle of the atmospheric parameters has been neglected as well. This can further affect the difference between day and night emissivity. We tested the effect of the neglected atmospheric opacity. Fig. 14 shows that including this parameter (atmospheric opacity) in the determination of $T_{\text {eff }}$ for $89 \mathrm{GHz}$ (H polarization) does not affect the answer significantly when compared to the proposed method. This suggests that the remaining differences are mostly due to neglect of the diurnal variations of the atmospheric parameters that are not included in this study.

One of the assumptions in this study is that the mean diurnal temperatures at the skin and deeper layers are the same (Eq. (7)). Several studies have been conducted to investigate the diurnal variation of soil temperature at different layers and contradictory results about this assumption have been reported. Some believe that heat conduction should produce the same mean diurnal temperature at all levels

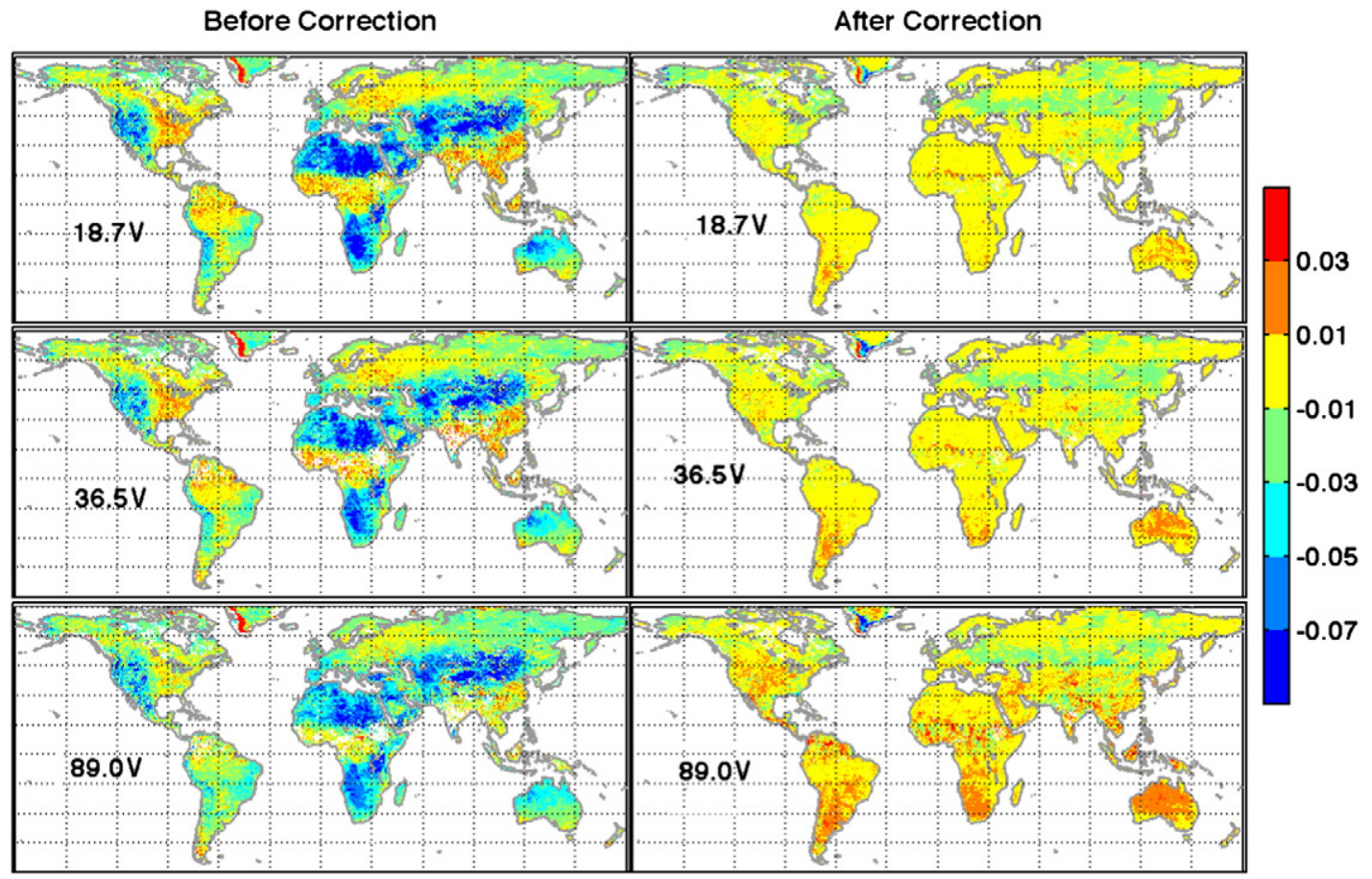

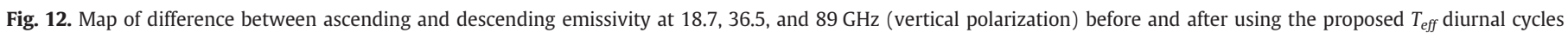
anomalies for July 2003 
Over the globe

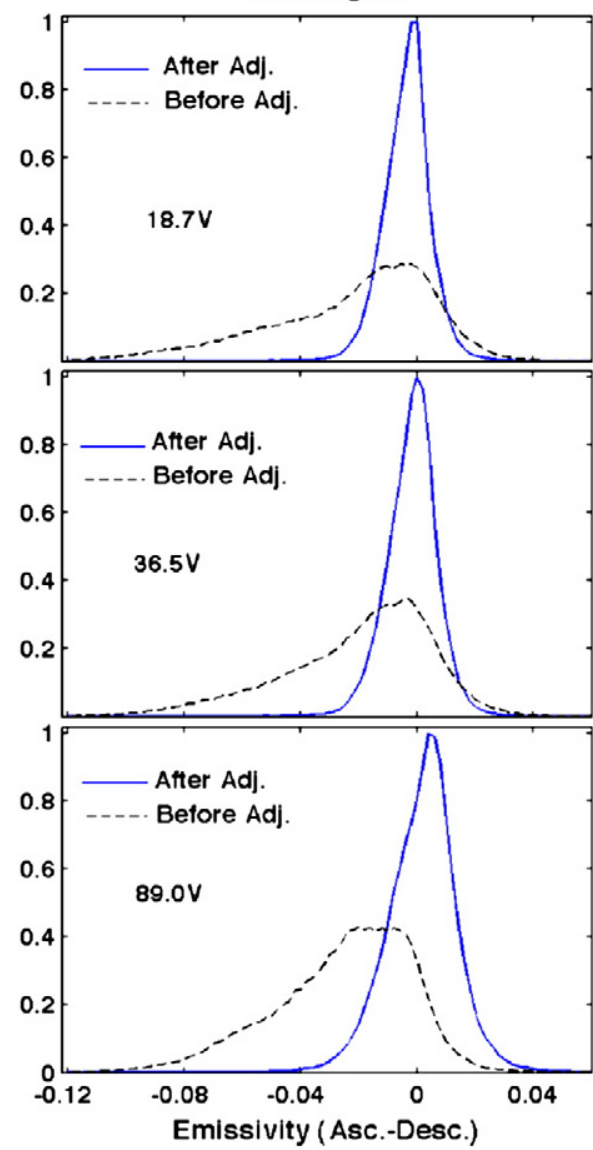

Desert regions

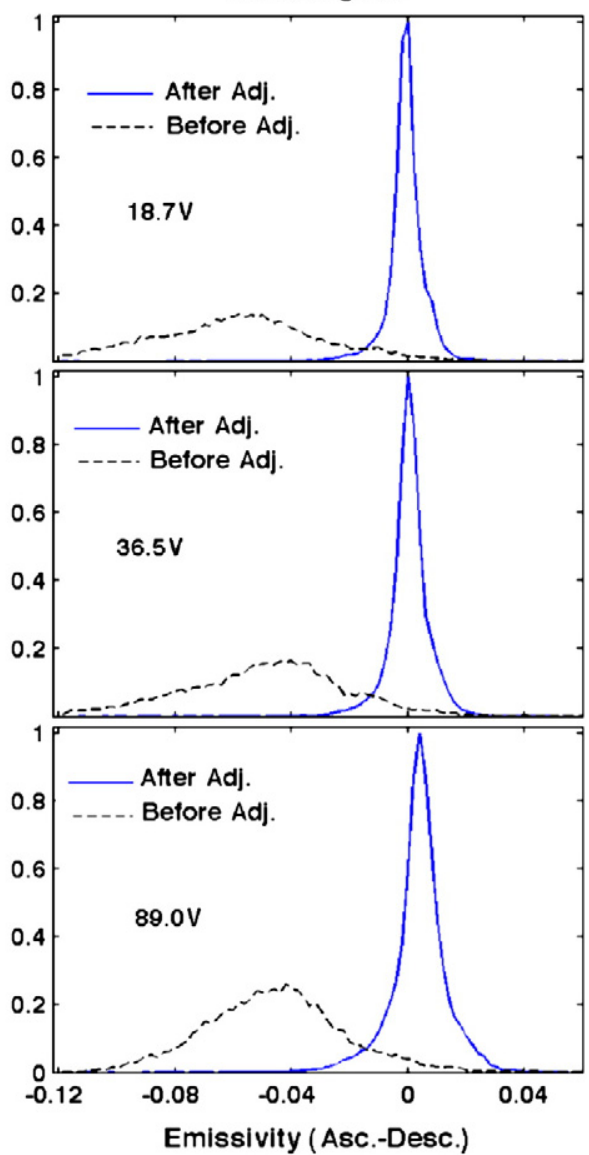

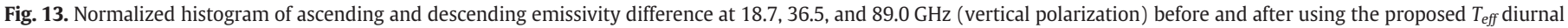
cycles anomalies for July 2003 over the globe and desert regions.

(Massman, 1993; Prigent et al., 1999) while other studies show that other sources and sinks could exist due to evaporations (Holmes et al., 2008; Rutten et al., 2010). For further investigation, ground measurements of soil temperature profile were analyzed (from http://www. mesonet.org). The results of ground measurements show that deeper layers have smaller amplitude and a phase lag compared to layers closer to the surface. Some differences in mean diurnal temperature of up to $3 \mathrm{~K}$ (between surface and depth of $30 \mathrm{~cm}$ ) in moderately vegetated regions have been recorded but the AMSR-E channel penetration depths are only a few centimeters in non-arid regions. In arid regions with greater penetration evaporation effects are negligible (Holmes et al., 2008; Rutten et al., 2010) and similar mean temperatures at deeper layers to the average of the skin temperature is expected. A sensitivity test shows that a possible $3 \mathrm{~K}$ disparity can change emissivity by 0.01 .

The other assumption in this study is that the emissivity or dielectric constant of the surface does not change with temperature between day

Table 2

Global mean and standard deviation of ascending and descending emissivity differences before and after applying the proposed $T_{\text {eff }}$ anomalies.

\begin{tabular}{lllll}
\hline Channel & $\begin{array}{l}\text { Global mean } \\
\text { of Asc.-Desc. } \\
\text { (After) }\end{array}$ & $\begin{array}{l}\text { Global mean } \\
\text { of Asc.-Desc. } \\
\text { (Before) }\end{array}$ & $\begin{array}{l}\text { Global Asc.-desc. } \\
\text { STD (After) }\end{array}$ & $\begin{array}{l}\text { Global Asc.-desc. } \\
\text { STD (Before) }\end{array}$ \\
\hline $18.7 \mathrm{~V}$ & -0.003 & -0.022 & 0.01 & 0.029 \\
$18.7 \mathrm{H}$ & -0.005 & -0.023 & 0.016 & 0.028 \\
$23.8 \mathrm{~V}$ & -0.002 & -0.025 & 0.01 & 0.028 \\
$36.5 \mathrm{~V}$ & -0.001 & -0.019 & 0.01 & 0.027 \\
$36.5 \mathrm{H}$ & -0.003 & -0.018 & 0.015 & 0.026 \\
$89.0 \mathrm{~V}$ & 0.003 & -0.024 & 0.013 & 0.025 \\
$89.0 \mathrm{H}$ & 0.002 & -0.024 & 0.014 & 0.026 \\
\hline
\end{tabular}

and night. Some studies have investigated the effect of temperature on the dielectric constant and have confirmed that for small and medium moisture values there is a negligible temperature effect on the dielectric constant (Or and Wraith, 1999; Pepin et al., 1995). For higher moisture values there is a tendency for soil bulk dielectric permittivity to decrease with temperature, which is consistent with the decrease of free water dielectric permittivity with the temperature increase. In this perspective, this assumption seems to be realistic as just arid and semi-arid regions

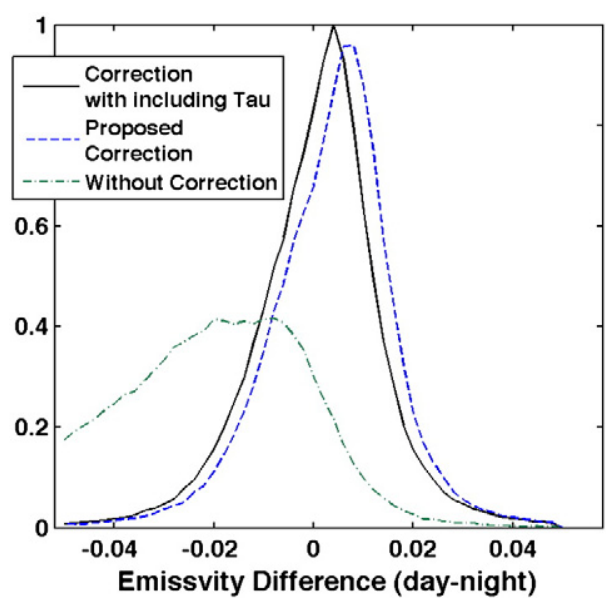

Fig. 14. Normalized histograms of day and night emissivity differences at $89.0 \mathrm{GHz}$ ( $\mathrm{H}$ polarization) using the proposed $T_{\text {eff }}$ anomalies with and without including atmospheric opacity in the correction. 
showed large differences between day and night due penetration depth effect and not because of temperature effect on the dielectric constant (Skierucha, 2011).

The effect of sensor calibration and inter-calibration differences among sensors was tested by applying up to $3 \mathrm{~K}$ difference in $T_{\text {eff }}$ anomalies. This analysis showed that results in terms of day and night emissivity estimates could be changed by $1 \%$.

In stable condition in terms of moisture, only small differences are expected between day and night observations. However, there is a diurnal variation of precipitation, which could cause a systematic difference of soil moisture. This surface moisture variation can affect the microwave brightness temperature. The shape of the $T_{\text {eff }}$ diurnal cycle anomalies is assumed constant, while the effects of the brightness temperature still can show the difference between emissivities during the day and night due to moisture content variation.

The proposed method in this study is limited to similar frequencies from SSM/I and AMSR-E, i.e. the lower frequencies at 6.925 and $10.65 \mathrm{GHz}$ (C- and X-bands) are not included. A possible approach to resolve the discrepancies at these lower frequencies might be to extrapolate the lookup table of $T_{\text {eff }}$ diurnal cycle anomalies to C- and $\mathrm{X}$-bands. Moreover, observations from WindSat and TMI, which have these lower frequency channels, could be used to construct $T b$ diurnal cycle at the lower frequencies. All steps including the PCA and generating the $T_{\text {eff }}$ diurnal cycle anomalies lookup table then can be applied. At these lower frequencies, emissivity is more sensitive to soil moisture and therefore soil moisture diurnal variation can affect the day and night emissivity differences (Jackson et al., 1997). Also, as is shown in Fig. 4, the depth of origination is similar for $\mathrm{V}$ and $\mathrm{H}$ polarization at the same frequency. To further simplifying the lookup table, average of $\mathrm{V}$ and $\mathrm{H}$ polarization $T_{\text {eff }}$ diurnal cycle anomalies can be used at each frequency for both $\mathrm{V}$ and $\mathrm{H}$ polarizations.

\section{Conclusion}

Microwave $T b$ diurnal variations for different channels were constructed and analyzed using PCA method. The first three PCA components represented the amplitude, length of the daytime, and the phase of the diurnal cycle. The spatial variations of the components are consistent with the moisture content and vegetation density of the surface. However, in some places such as sand dunes smaller $\mathrm{Tb}$ diurnal amplitude were observed which are not consistent with diurnal variation of the skin temperature. This study confirms that microwave emissions come from layers deeper than the surface skin depending on the frequency and the media. To retrieve microwave land emissivity, infrared surface skin temperatures have been used as surface physical temperature. This study showed that the diurnal variations of microwave and infrared emissivities in dry regions differ significantly, leading to big differences between day and night emissivities. The more vegetated/moister the region, the less the differences between infrared and microwave temperatures diurnal variations and the less apparent emissivity diurnal variation.

A lookup table of $T b$ diurnal variation (as anomalies with respect to the daily mean values) was developed based on the directly observed diurnal variation of passive microwave brightness temperature over the whole globe. The $T_{\text {eff }}$ diurnal cycle anomalies can be added to the daily average of the skin temperature to find the $T_{\text {eff }}$ for each channel and month of the year. Integrating the developed $T_{\text {eff }}$ anomaly lookup tables in emissivity retrievals reduced the differences between day and night emissivities to less than 0.01 in contrast to the results based on using the infrared thermal temperature as physical temperature. The results of the present study can be extended to lower frequencies (C- and X-bands) by using other sensors such as WindSat and TMI. This study focused on $T b$ diurnal variation using conical scanning sensors with constant overpass times. Cross-track microwave sensors with variable daily overpass times can also provide $\mathrm{Tb}$ diurnal variation.

\section{Acknowledgments}

This study was partially supported by National Oceanic and Atmospheric Administration (NOAA) under grant NA06OAR4810162, NASA Energy and Water Study (NEWS) under grant NNXD7AO90G. The authors would like to thank Leslie Moy for her valuable comments on this manuscript.

\section{References}

Aires, F., Prigent, C., \& Rossow, W. B. (2004). Temporal interpolation of global surface skin temperature diurnal cycle over land under clear and cloudy conditions. Journal of Geophysical Research-Atmospheres, 109.

Boukabara, S. A., Weng, F. Z., \& Liu, Q. H. (2007). Passive microwave remote sensing of extreme weather events using NOAA-18 AMSUA and MHS. IEEE Transactions on Geoscience and Remote Sensing, 45, 2228-2246.

Colton, M. C., \& Poe, G. A. (1999). Intersensor calibration of DMSP SSM/I's: F-8 to F-14, 1987-1997. IEEE Transactions on Geoscience and Remote Sensing, 37, 418-439.

Entekhabi, D., Njoku, E. G., O'Neill, P. E., Kellogg, K. H., Crow, W. T., Edelstein, W. N., et al. (2010). The soil moisture active passive (SMAP) mission. Proceedings of the IEEE, 98, 704-716.

Fily, M., Royer, A., Goita, K., \& Prigent, C. (2003). A simple retrieval method for land surface temperature and fraction of water surface determination from satellite microwave brightness temperatures in sub-arctic areas. Remote Sensing of Environment, $85,328-338$.

Galantowicz, J. F., Moncet, J. -L., Liang, P., Lipton, A. E., Uymin, G., Prigent, C., et al. (2011). Subsurface emission effects in AMSR-E measurements: Implications for land surface microwave emissivity retrieval. Journal of Geophysical Research-Atmospheres, 116.

Geer, A. J., Bauer, P., \& Bormann, N. (2010). Solar biases in microwave imager observations assimilated at ECMWF. IEEE Transactions on Geoscience and Remote Sensing, $48,2660-2669$

Grody, N. C., \& Weng, F. (2008). Microwave emission and scattering from deserts: Theory compared with satellite measurements. IEEE Transactions on Geoscience and Remote Sensing, 46, 361-375.

Holmes, T. R. H., Owe, M., De Jeu, R. A. M., \& Kooi, H. (2008). Estimating the soil temperature profile from a single depth observation: A simple empirical heatflow solution. Water Resources Research, 44

Jackson, T. J., Oneill, P. E., \& Swift, C. T. (1997). Passive microwave observation of diurnal surface soil moisture. IEEE Transactions on Geoscience and Remote Sensing, 35, 1210-1222.

Jimenez, C., Catherinot, J., Prigent, C., \& Roger, J. (2010). Relations between geological characteristics and satellite-derived infrared and microwave emissivities over deserts in northern Africa and the Arabian Peninsula. Journal of Geophysical Research-Atmospheres, 115.

Jolliffe, I. T. (2002). Principal Component Analysis. New York: Springer.

Karbou, F., Gerard, E., \& Rabier, F. (2006). Microwave land emissivity and skin temperature for AMSU-A and -B assimilation over land. Quarterly Journal of the Royal Meteorological Society, 132, 2333-2355.

Liebe, H. J. (1989). MPM-An atmospheric millimeter-wave propagation model. International Journal of Infrared and Millimeter Waves, 10, 631-650.

Liebe, H. J., Hufford, G. A., \& Cotton, M. G. (1993). Propagation modelling of moist air and suspended water/ice particles at frequencies below $1000 \mathrm{GHz}$. presented at the Specialist Meeting of the Electromagnetic Wave Propagation Panel Symposium, Palma de Mallorca, Spain.

Massman, W. J. (1993). Periodic temperature-variations in an inhomogeneous soil-A comparison of approximate and exact analytical expressions. Soil Science, 155, 331-338.

Matthews, E. (1983). Global vegetation and land-use data-base for climate studies. Bulletin of the American Meteorological Society, 64, 793-794.

McCollum, J. R., \& Ferraro, R. R. (2005). Microwave rainfall estimation over coasts. Journal of Atmospheric and Oceanic Technology, 22, 497-512.

Min, O. L., Lin, B., \& Li, R. (2010). Remote sensing vegetation hydrological states using passive microwave measurements. IEEE Journal of Selected Topics in Applied Earth Observations and Remote Sensing, 3, 124-131.

Moncet, J., Liang, P., Galantowicz, A., Lipton, A., Uymin, G., Prigent, C., et al. (2011). Land surface microwave emissivities derived from AMSR-E and MODIS measurements with advanced quality control. Journal of Geophysical Research-Atmospheres, 116.

Njoku, E. G., \& Entekhabi, D. (1996). Passive microwave remote sensing of soil moisture. Journal of Hydrology, 184, 101-129.

Njoku, E. G., Jackson, T. J., Lakshmi, V., Chan, T. K., \& Nghiem, S. V. (2003). Soil moisture retrieval from AMSR-E. IEEE Transactions on Geoscience and Remote Sensing, 41, 215-229.

Njoku, E. G., Stacey, J. M., \& Barath, F. T. (1980). The Seasat scanning multichannel microwave radiometer (SMMR): Instrument description and performance. IEEE Journal of Oceanic Engineering, 5, 100-115.

Norouzi, H., Temimi, M., Rossow, W. B., Pearl, C., Azarderakhsh, M., \& Khanbilvardi, R. (2011). The sensitivity of land emissivity estimates from AMSR-E at C and X bands to surface properties. Hydrology and Earth System Sciences, 15, 3577-3589.

Or, D., \& Wraith, J. M. (1999). Temperature effects on soil bulk dielectric permittivity measured by time domain reflectometry: A physical model. Water Resources Research, 35, 371-383.

Papa, F., Prigent, C., Rossow, W. B., Legresy, B., \& Remy, F. (2006). Inundated wetland dynamics over boreal regions from remote sensing: the use of Topex-Poseidon 
dual-frequency radar altimeter observations. International Journal of Remote Sensing, $27,4847-4866$.

Pepin, S., Livingston, N. J., \& Hook, W. R. (1995). Temperature-dependent measurement errors in time-domain reflectometry determinations of soil-water. Soil Science Society of America Journal, 59, 38-43.

Prigent, C., Aires, F., Rossow, W., \& Matthews, E. (2001). Joint characterization of vegetation by satellite observations from visible to microwave wavelengths: A sensitivity analysis. Journal of Geophysical Research-Atmospheres, 106, 20665-20685.

Prigent, C., Jaumouille, E., Chevallier, F., \& Aires, F. (2008). A parameterization of the microwave land surface emissivity between 19 and $100 \mathrm{GHz}$, anchored to satellitederived estimates. IEEE Transactions on Geoscience and Remote Sensing, 46, 344-352.

Prigent, C., Rossow, W. B., \& Matthews, E. (1997). Microwave land surface emissivities estimated from SSM/I observations. Journal of Geophysical Research-Atmospheres, $102,21867-21890$.

Prigent, C., Rossow, W. B., \& Matthews, E. (1998). Global maps of microwave land surface emissivities: Potential for land surface characterization. Radio Science, 33, 745-751.

Prigent, C., Rossow, W. B., Matthews, E., \& Marticorena, B. (1999). Microwave radiometric signatures of different surface types in deserts. Journal of Geophysical Research-Atmospheres, 104, 12147-12158.

Rossow, W. B., \& Schiffer, R. A. (1991). ISCCP cloud data products. Bulletin of the American Meteorological Society, 72, 2-20.
Rossow, W. B., \& Schiffer, R. A. (1999). Advances in understanding clouds from ISCCP. Bulletin of the American Meteorological Society, 80, 2261-2287.

Rutten, M. M., Steele-Dunne, S. C., Judge, J., \& van de Giesen, N. (2010). Understanding heat transfer in the shallow subsurface using temperature observations. Vadose Zone Journal, 9, 1034-1045.

Skierucha, W. (2011). Electromagnetic Waves. : InTech.

Stephen, H., Ahmad, S., \& Piechota, T. C. (2010). Land surface brightness temperature modeling using solar insolation. IEEE Transactions on Geoscience and Remote Sensing, 48, 491-498.

Tedesco, M., \& Kim, E. J. (2006). Retrieval of dry-snow parameters from microwave radiometric data using a dense-medium model and genetic algorithms. IEEE Transactions on Geoscience and Remote Sensing, 44, 2143-2151.

Weng, F. Z. (2007). Advances in radiative transfer modeling in support of satellite data assimilation. Journal of the Atmospheric Sciences, 64, 3799-3807.

Weng, F. Z., Yan, B. H., \& Grody, N. C. (2001). A microwave land emissivity model. Journal of Geophysical Research-Atmospheres, 106, 20115-20123.

Wilheit, T., Kummerow, C. D., \& Ferraro, R. (2003). Rainfall algorithms for AMSR-E. IEEE Transactions on Geoscience and Remote Sensing, 41, 204-214.

Zhang, L. X., Zhao, T. J., Jiang, L. M., \& Zhao, S. J. (2010). Estimate of phase transition water content in freeze-thaw process using microwave radiometer. IEEE Transactions on Geoscience and Remote Sensing, 48, 4248-4255. 